\title{
FACTORS AFFECTING TO ORGANIC FOOD BUYING INTENTION
}

\author{
K.G.N.W. Abeyrathna ${ }^{1}$ 西 \\ ${ }^{1}$ Asia Banking School-Maharagama, Colombo, Sri Lanka
}

\section{ABSTRACT}

Organic food is one latest food cultures of Sri Lankan community due to the non-communicable diseases of the inorganic foods. After the green revolution and plantation culture of the country farmers used to use the pesticides, agrochemicals, Insecticides, Weedicides, Fungicides to manage the crops. After the green revolution, multinational companies who are based on the Monsanto concept started to distribute their chemicals under the faith of high yield. Today Sri Lanka is the country which has the most agriculture based chemical consumers in the world.

Keywords: Organic Food, Diseases, Farmers

Received 3 April 2021

Accepted 18 April 2021

Published 30 April 2021

Corresponding Author

K.G.N.W. Abeyrathna, asiabankings

chool@gmail.com

DOI 10.29121/

granthaalayah.v9.i4.2021.3900

Funding: This research received no specific grant from any funding agency in the public, commercial, or not-for-profit sectors.

Copyright: (C) 2021 The Author(s). This is an open access article distributed under the terms of the Creative Commons Attribution License, which permits unrestricted use, distribution, and reproduction in any medium, provided the original author and source are credited.

OPEN

\section{INTRODUCTION}

According to the Sri Lankan agro statistics Sri Lankan farmers and other cultivators used fertilizer 655,844 tons, 4474 tons of fertilizer liquid, 1192.92 tons of herbicides, 985.40 tons of pesticides, 822.4 tons of insecticides in 2018. And in addition, the crop farms and chicken farms also use the chemicals to grow up the chickens. Due to the heavy use of chemicals, crop farming farmers and consumers are suffering from the different kind of cancers and liver failures. Thirty-eight million deaths reported around the world due to non-communicable diseases and especially unhealthy foods was one of the major reasons World Health Statistics (2015) (2021). Today, consumers more concerned for their health due to the cancers and other illnesses then they are changing their food and nutrition patterns towards the organic foods. Organic foods are the food grown without chemical fertilizers, pesticides, preservatives and synthetic food enhancers Kapuge (2016). Due to the customer request, nowadays, farmers are cultivating organic foods around the country. Organic farmers do not utilize the any kind of chemicals for the cultivation and they use organic fertilizers for the cultivation. Organic food consists only of one third of pesticides that conventional food does Baker et al. (2004). Due to the less usage or zero usage of the fertilizer, organic foods became healthier to the consumers. With 
the uprising consumers knowledge of the organic foods, the demand of the organic foods is also higher. Consumers with the willingness of the natural foods or green consumption practice are selected the organic foods (Lockie, 2004). To grow up the consumers trust there are few organic certification institutes are operating in the country. Village based community is able to grow up organic vegetables in their home garden or purchase from the nabor farms but urban community specially in Colombo related households have to purchase organic foods from the Colombo race course Saturday fare or Colombo 07 Sambodhi viharaya organic fare. An apart of those organic fare supermarket sells some plenty of organic foods.

\section{LITERATURE REVIEW}

A growing consumption of organic food has emerged as the new food culture in human life as general public has to concern for the human health, food safety and environmental concern attributes in this decade comparing with the previous decade. With the development of urbanization and green revolution concepts and globalization, people have to say good bye for the self-sufficient life and they had to purchase every good from the retail shops. For answer the highest demand farmers and mas scale farms used to use the agrochemicals to enhance the crops due to this interconnectedness consumers have to face to the different kind of non-communicable deceases. The concept of organic food emerged with the above agrochemical problem. Organic food means which are foods grown without the agrochemical or less agro chemical due to that taste, quality, nutrition of the organic food is differ than other conventional foods. There are different sensory qualities of organic food to conventional food Bourn and Prescott (2002). organic food market is speedily growing up market Baker et al. (2004).

The reason of the development of organic sector is growing interest of the consumers due to several reasons. Basically, conventional food, producers use pesticide in maximum limits then consumers refuse the typical vegetables, fruits and other foods. Consumers show their dislikes on agrochemicals, hormones percentages on animal production and artificial additives in fruits and vegetables Naspetti and Zanoli (2006). currently consumers choose organic foods due to the chemical, pesticide and unhealthy ingredients of the conventional foods because today consumers think about their health and safety than earlier age due to the accelerating health problems of the world then people choose the organic foods. Researchers have found that consumers prefer organic food to conventional foods today Magnusson (2004). Some consumers believe that organic foods are fresh and high quality and full of nutrition than conventional foods because of organic farmers never use the chemicals to grow up the foods due to this reason organic foods are available to consume in any time and they never spoil as conventional foods within short period of time. Most consumers revealed that freshness and taste are their food choice Torjusen et al. (2001). Due to that consumers are willing to consume the organic foods because organic foods are 
fresh more than the conventional foods.

Health is the most important factor in this decade. Medical professionals identified that non communicable deceases are the major trend of this decade. The deceases from unhealthy consumption and foods with chemicals are the main reason According to the advice of the health professionals the consumers have to convert the consumption pattern towards the organic foods. Organic foods do not contain the any kind of pesticide or other chemicals which are unsuitable for the human health. Health consciousness is the major factor for buying organic foods Kapuge (2016). Davis (1995) also emphasized that health concern is the major motivator for buying organic foods. Recently there are developing concept of the veganism. Under the veganism concept consumers prohibit the killing animals for the food productions. Inorganic food industry kills millions of insects for the cultivation of the crops due to that reason some people dislike to killing and harassment of the animal then they prefer the organic foods because of organic foods industries never harm to the any animals in the earth. Organic food consumption related to environmentalism, Veganism and alternative medicine Cicia et al. (2002). People who follow the above beliefs prefer the organic food culture. Organic foods producers prohibit the pesticide, fungicide, herbicides, fertilizers, antibiotics and hormones for the productions. Due to this organic food contains natural taste and environmental and animal conserve and then people prefer them. According to above researchable ideas consumers prefer organic foods for their lifestyle. On the other hand, some people refuse the organic foods due to the several factors mainly price of the organic foods are higher than the conventional foods. Consumers accuse that they cannot afford organic food due to the high price than conventional foods Whitehead and Nicholson (2001). but most of consumers don't care for the money because they are concerned with the quality of the foods. Increasing trend of the organic market is consumers are willing to pay a premium for organic food Batte et al. (2007). A growing trend of organic food has contributed new research studies compared to the conventional foods because health, nutrition, food safety, environmental concern, taste, freshness are more important factors today.

\section{METHODOLOGY}

This research study used the survey design. Basically, it explored the organic food users background consumption patterns. An apart of that identified the relationship of the purchasing intention, Food security, Healthy, freshness, Nutrition value with the organic food buying behavior. for the data collection process researcher had to use the two famous organic fair's in Colombo. Race coure colombo 07 saturday organic fair is the most famous fair in Colombo and Gregary road temple fair at Colombo 07 also has permanant customer base for the organic foods. Consumers of the above fare selected to get theere ides of the organic food buyimg behaviour. structured questionare has given to the above one handred and fifteen(115) selected 
sample of consumers to represent the organic food consumers of the country.

The research questionnaire consists of seven (7) parts with the demographic details. There were forty-five (45) quantitative questions included in the questionnaire. For measuring the relative performance of the respondents, all questions were asked to be rated on a seven-point Likert scale where ( $7=$ Strongly agree, $6=$ Highly agree, $5=$ Agree $4=$ Neutral $3=$ disagree $2=$ Highly disagree $1=$ Strongly agree) . Descriptive statistics, Chi square, and Pearson correlation, were used to data presentation and analysis. SPSS and Micro soft excel used to above data presentation and analysis.

\section{CONCEPTUAL FRAMEWORK}

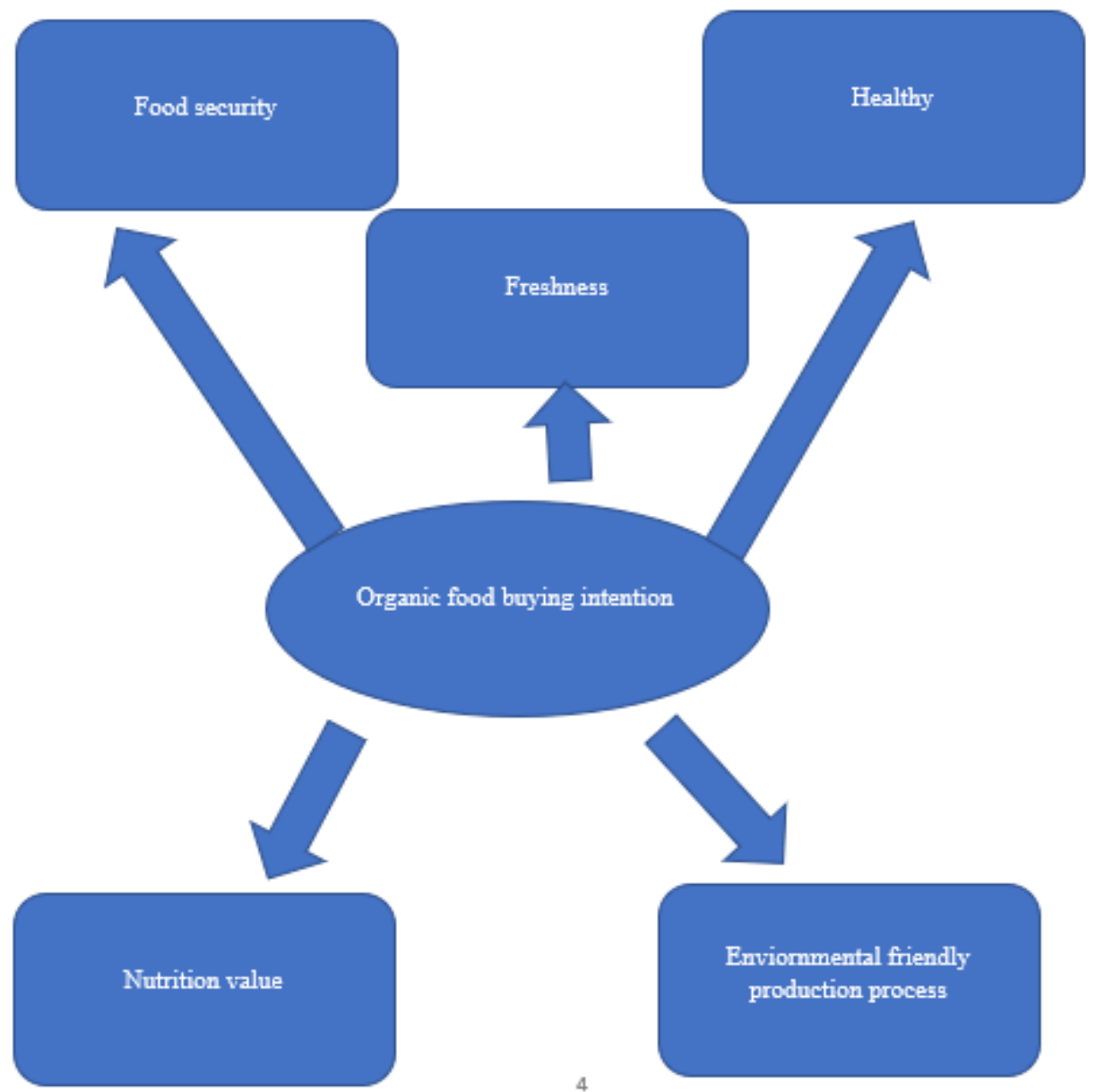

Figure 1 Source: By Author Conceptual framework of the study represents the relationship between each variable such as nutrition value, environmentally friendly, freshness, food security, healthy and the organic food buying intention. 


\section{RESULT AND DISCUSSION}

To carry on with the descriptive analysis used the demographic details of the respondents of this study.

Total interviewers 115 (One hundred and fifteen) were selected for the survey and 34.78 percent were female and 65.2 were male respondents.

Table 1 D emographic characteristics of the respondents

\begin{tabular}{|c|c|c|}
\hline \multicolumn{2}{|c|}{ Characteristics } & \multirow{2}{*}{$\begin{array}{c}\text { Percentages } \\
65.2\end{array}$} \\
\hline Gender & Male & \\
\hline & Female & 34.78 \\
\hline \multirow[t]{4}{*}{ Religion } & Buddhist & 80 \\
\hline & Hindu & 3.49 \\
\hline & Catholic & 8.69 \\
\hline & Others & 7.82 \\
\hline \multirow[t]{4}{*}{ Ethnicity } & Sinhalese & 86.95 \\
\hline & Hindu & 2.6 \\
\hline & Muslims & 3.4 \\
\hline & Others & 7.05 \\
\hline \multirow[t]{6}{*}{ Age } & $11-20$ & 19.13 \\
\hline & $21-30$ & 9.56 \\
\hline & $31-40$ & 28.6 \\
\hline & $41-50$ & 13.04 \\
\hline & $51-60$ & 18.26 \\
\hline & $60>$ & 11.41 \\
\hline \multirow[t]{4}{*}{ Education } & Primary & 6.08 \\
\hline & Diploma & 34.78 \\
\hline & Secondary & 15.65 \\
\hline & Degree & 43.49 \\
\hline \multirow{6}{*}{$\begin{array}{l}\text { Where do you buy organic } \\
\text { food }\end{array}$} & Super Market & 56 \\
\hline & Cart & 16 \\
\hline & Fare & 13 \\
\hline & Travelling carts & 21 \\
\hline & shop & 6 \\
\hline & Other & 03 \\
\hline
\end{tabular}

\section{Source: Survey Data}

Table 2 shows the results oforganic food in each attribute. According to These results that the highest mean of 5.808 recorded for healthy attribute. This value explains the healthy attribute is highly related to the organic food buying decision. Purchasing intention for buying organic foods became at 2nd rank with score of 5.7196 Consequently, it shows that nutrition value and organic food buying behavior of 5.4098 at 3rd rank. Consecutively food security, environmentally friendly production process, freshness, records 5.6354, 5.3726, 5.179, values. The lowest mean records selected organic food buying with mean of 2.696 however, all variables are perceived by respondent at agreed level on organic food buying behavior. While busines failure with score of 3.005 which reveals that respondents generally aware 
with the organic food.

\begin{tabular}{lcc}
\hline Table 2 Mean and Standard deviation & \\
\hline & Mean & Standard Deviation \\
\hline Education Level & 2.913 & 1.1514 \\
\hline Cancer Protection & 2.722 & 1.9036 \\
Selected organic food buying & 2.696 & 1.7177 \\
purchasing intention & 5.7196 & 1.5275 \\
\hline Food security & 5.6354 & 1.4309 \\
Healthy & 5.808 & 1.3808 \\
freshness & 5.179 & 1.3450 \\
\hline Nutrition value & 5.4098 & 1.4083 \\
\hline Enviornmental friendly production process & 5.3726 & 1.4486 \\
\hline
\end{tabular}

Source: Survey Data

To find the relationship, each variables and organic food buying behavior, this research applies the Pearson correlation for check the relationship of each variables. According to the results Environmentally friendly attribute $(r=0.61870$ records the highest correlation with the organic food buying behavior. Least correlation of $(\mathrm{r}=$ 0.254) records the Availability for purchase and organic food buying behavior.

\section{Table 3 Correlation of the variables}

\begin{tabular}{|lc|}
\hline Education Level and purchasing intention & 0.363 \\
\hline Buying places and Freshness & 0.1767 \\
\hline Enviornmental friendly production process And purchasing intention & 0.6184 \\
\hline Availability for Purchasing & 0.254 \\
\hline Freshness and nutrition value & 0.5682
\end{tabular}

**Correlation is significant at the 0.01 level ( 2 tailed).

Source: Survey Data

\section{CONCLUSIONS AND RECOMMENDATION}

In this research author attempted to analyze the reasons for organic food demand through the measurement of food security, healthy, freshness, nutrition value, environmentally friendly. the analysis result reveals that organic food consumption and above factors have positive relationship. Findings of the study reveal that all considered attributes are positively co-related Mean and standard deviation of the considered data reveal the significant correlation of the considered factors. Consumers should be concerned about the certification of the organic foods for better consumption because some vegetable sellers sell the goods with the fake certificate under the name of the organic. Government should try to minimize the imports of chemicals and pesticides because Sri Lanka no need more fertilizers for the cultivation. 


\section{REFERENCES}

Baker, S., Thompson, K. E., Engelken, J., \& Huntley, K. (2004). Mapping the values driving organic food choice. European Journal of Marketing, 38(8), 995-1012. Retrieved from https://dx.doi.org/10.1108/03090560410539131 10.1108/03090560410539131

Batte, M. T., Hooker, N. H., Haab, T. C., \& Beaverson, J. (2007). Putting their money where their mouths are: Consumer willingness to pay for multi-ingredient, processed organic food products. Food Policy, 32(2), 145-159. Retrieved from https://dx.doi.org/10.1016/ j.foodpol.2006.05.003 10.1016/j.foodpol.2006.05.003

Bourn, D., \& Prescott, J. (2002). A Comparison Of The Nutritional Of The Nutritional Value, Sensory Qualities And Food Safety Of Organically And Conventionally Produced Foods. Critical Reviews In Food Science And Nutrition, 42, 1-34.

Cicia, G., Giudice, D., Scarpa, T., \& R. (2002). Utility Model Under Preference Heterogeneity And Choice Correlation From Rank-Orderings. British Food Journal, 104(3), 213-213.

Davis, A. (1995). Who Buys Organic Food? A Profile Of The Purchasers Of Organic Food In N. Ireland. British Food Journal, 97(10), 17-23.

Kapuge, K. D. L. R. (2016). Determinants of Organic Food Buying Behavior: Special Reference to Organic Food Purchase Intention of Sri Lankan Customers. Procedia Food Science, 6(6), 303-308. Retrieved from https://dx.doi.org/10.1016/j.profoo.2016.02.060 10 .1016/j.profoo.2016.02.060

Lockie, S., Lyons, K., Lawrence, G., \& Mummery, K. (2002). Eating 'Green': Motivations behind organic food consumption in Australia. Sociologia Ruralis, 42(1), 23-40. Retrieved from https://dx.doi.org/10.1111/1467-9523.00200 10.1111/1467-9523.00200

Magnusson, M. (2004). Consumer Perception Of Organic And Genetically Modified Foods. In Consumer Perception OfOrganic And Genetically Modified Foods: Jealth And Environmental Considerations. Uppsala.

Naspetti, S., \& Zanoli, R. (2006). Marketing Dynamics Within The Global Trading System. In Organic Food Quality And Safety Perception Throughout Europe, EAAE Seminar 'Marketing Dynamics Within The Global Trading System: New Perspectives. Greece.

Torjusen, H., Lieblein, G., Wandel, M., \& Francis, C. A. (2001). Food system orientation and quality perception among consumers and producers of organic food in Hedmark County, Norway. Food Quality and Preference, 12(3), 207-216. Retrieved from https:// dx.doi.org/10.1016/s0950-3293(00)00047-1 10.1016/s0950-3293(00)00047-1

Whitehead, P., \& Nicholson, S. (2001). Niche Or Mainstream. In Organic Food: Niche Or Mainstream. IGD, Letchmore Heath Watford.

World Health Statistics (2015). (2021, sep 25). Gho-Documents/World-Health-StatisticReports/World-Health. Retrieved from Https://Www.Who.Int/Docs/Default-Source/ Gho-Documents/World-Health-Statistic-Reports/World-Health-Statistics-2015.Pdf 